\title{
Removal of Textile Dyes from Aqueous Solution by Heterogeneous Photo-Fenton Reaction Using Modified PAN Nanofiber Fe Complex as Catalyst
}

\author{
Xueting Zhao, ${ }^{1,2}$ Yongchun Dong, ${ }^{1}$ Bowen Cheng, ${ }^{1,2}$ and Weimin Kang ${ }^{1,2}$ \\ ${ }^{1}$ School of Textiles, Tianjin Polytechnic University, Tianjin 300387, China \\ ${ }^{2}$ State Key Laboratory of Hollow Fiber Membrane Materials and Processes, Tianjin Polytechnic University, Tianjin 300387, China \\ Correspondence should be addressed to Bowen Cheng; chengbowen@tjpu.edu.cn
}

Received 10 July 2013; Revised 20 September 2013; Accepted 6 October 2013

Academic Editor: Meenakshisundaram Swaminathan

Copyright ( $\odot 2013$ Xueting Zhao et al. This is an open access article distributed under the Creative Commons Attribution License, which permits unrestricted use, distribution, and reproduction in any medium, provided the original work is properly cited.

\begin{abstract}
The modified PAN nanofiber Fe complex was prepared by the amidoximation and Fe coordination of PAN nanofiber was obtained using electrospinning technique and then used for the heterogeneous Fenton degradation of textile dyes as a novel catalyst. Some main factors affecting dye degradation such as Fe content of catalyst, irradiation intensity, $\mathrm{H}_{2} \mathrm{O}_{2}$ initial concentration, the solution $\mathrm{pH}$ as well as dye structure, and initial concentration were investigated. UV-Vis spectrum analysis and TOC measurement were also used to evaluate the dye degradation process. The results indicated that the modified PAN nanofiber Fe complex exhibited a much better catalytic activity for the heterogeneous Fenton degradation of textile dyes than the Fe complex prepared with conventional PAN yarns in the dark or under light irradiation. Increasing Fe content of catalyst or irradiation intensity would accelerate the dye degradation. And the highest degradation efficiency was obtained with $3.0 \mathrm{mmol} \mathrm{L}{ }^{-1} \mathrm{H}_{2} \mathrm{O}_{2}$ at $\mathrm{pH}$ 6. Moreover, this complex was proved to be a universal and efficient catalyst for degradation of three classes of textile dyes including azo dye, anthraquinone dye, and triphenylmethane dye. Additionally, the dye mineralization was also significantly enhanced in the presence of this complex.
\end{abstract}

\section{Introduction}

The dyeing wastewaters containing remarkable concentration of organic dyes are often produced by the textile industry around the world. It is well known that these dyes are toxic and nonbiodegradable to aquatic animals and plant [1-4]. Therefore, the treatment of dyeing wastewaters has become a research focus in the field of environment research in recent years. Various physically or mechanically based techniques (e.g., activated carbon adsorption, coagulation/flocculation, or membrane separation) have been extensively utilized. However, they only do a phase transfer of the pollutants. Compared with these techniques, Fenton and photo-Fenton processes as the advanced oxidation technologies can potentially complete the mineralization of organic pollutants in water. Moreover, the heterogeneous Fenton technology is replacing the homogeneous system because of its special advantages on a wide range of $\mathrm{pH}$ adaptability and easy recycling use [5]. The heterogeneous Fenton catalysts can be obtained by immobilizing Fe ions on the polymer substrates such as Nafion membrane and fibrous materials. During the past decade years, we have been devoted to exploring the polyacrylonitrile (PAN) fiber supported Fenton catalysts. And the resulting modified PAN fiber Fe complexes have been considered as the effective heterogeneous Fenton catalysts with low cost [6]. But this catalyst suffers from some problems, such as low specific surface area and low utilization stability. Therefore, it is necessary to explore new heterogeneous catalysts with higher performance for the dye degradation using the polymer materials with larger surface area as the support substrates. On the other hand, PAN nanofiber is regarded as one of the attractive fibrous materials owing to its excellent characteristics including large surface area, remarkably high porosity, and high permeability compared with conventional fibers [7, 8]. It has been applied widely in fine filtration $[9,10]$, enzyme immobilization 
[11-14], and adsorptive membranes [15-18]. However, the detailed information regarding PAN nanofiber as the supported material for heterogeneous Fenton catalyst is very limited. In the present work, PAN nanofibers were firstly prepared by the electrospinning technique. PAN nanofiber Fe complex was then produced by its surface modification and metal coordination. Moreover, the activity of this complex was investigated as a heterogeneous Fenton catalyst for the oxidative degradation of the dye with $\mathrm{H}_{2} \mathrm{O}_{2}$. Finally, some factors affecting the dye degradation such as Fe content of catalyst, light irradiation, $\mathrm{H}_{2} \mathrm{O}_{2}$ initial concentration as well as structure and initial concentration of the dyes used were optimized and discussed.

\section{Experimental}

2.1. Materials and Reagents. PAN knitting bulky yarn (PAN yarn) that consisted of twisted PAN fibers was obtained from Shanghai Shilin Spinning Company. N,Ndimethylformamide (DMF), hydroxylamine hydrochloride, hydrogen peroxide $(30 \%)$, and ferric chloride were of laboratory agent grade. Three kinds of textile dyes including Reactive Red 195 (RR 195), Reactive Blue 4 (RB 4), and Acid Blue 7 (AB 7) were commercially available and purified by reprecipitation method in this experiment. Their molecular structures are presented in Figure 1. Double distilled and deionized water was used throughout the study.

2.2. Electrospinning of PAN Nanofiber. According to [11, 19], the $14 \mathrm{wt} \%$ solution of PAN was prepared by dissolving PAN yarn in DMF under constant stirring at room temperature for $24 \mathrm{~h}$. The obtained PAN solution was added to a $10 \mathrm{~mL}$ glass syringe with a blunt needle. The PAN solution flow rate was controlled by a microinfusion pump to be $0.30 \mathrm{mlh}^{-1}$. The high-voltage supplier was used to connect the grounded collector and metal needles for forming electrostatic fields. The used voltage was $20 \mathrm{kV}$ and a piece of flat aluminum foil on the grounded collection roller was placed about $15 \mathrm{~cm}$ below the tip of the needle to collect the nanofiber. A jet of PAN solution came out from the needle tip at a critical voltage and was collected on the aluminum foil. The PAN nanofibers were obtained after DMF evaporation.

2.3. Preparation of Modified PAN Nanofiber Fe Complex. On the basis of our previous work [20], PAN nanofibers were amidoximated using a mixed solution containing hydroxylamine hydrochloride and sodium hydroxide in a $250 \mathrm{~mL}$ flask with a thermometer and agitator for at $1-2 \mathrm{~h}$ at $68^{\circ} \mathrm{C}$. And then the resulting amidoximated PAN nanofiber (denoted as AO-n-PAN) was washed several times with distilled water and dried under vacuum at $50^{\circ} \mathrm{C}$. The degree of the conversion from nitrile groups to amidoxime groups of the AO-nPAN was calculated to be $41.21 \%$ [19]. The obtained AO-nPAN nanofiber was immersed in an aqueous solution of ferric chloride under continuous agitation at $50^{\circ} \mathrm{C}$ for $2 \mathrm{~h}$ in order to produce the amidoximated PAN nanofiber Fe complex (denoted as Fe-AO-n-PAN). The residual concentration of $\mathrm{Fe}^{3+}$ ions in solution after coordination was determined using a VISTA MPX inductively coupled plasma optical emission spectrometer (ICP-OES, Varian Corp., USA) for calculating the Fe content $\left(Q_{\mathrm{Fe}}\right)$ of Fe-AO-n-PAN.

2.4. Characterization of Modified PAN Nanofiber Fe Complex. The surface morphology of Fe-AO-n-PAN was examined by a field emission scanning electron microscope (FE-SEM) (S-4800, Hitachi Co., Japan). The average diameter of PAN nanofibers was determined by analyzing the SEM images with an image analyzing software (Image-Pro Plus, Media Cybernetics Inc.) [21]. Composition of Fe-AO-n-PAN was verified by using a Nicolet Magana-560 Fourier transform spectrometer (Nicolet Instrument Co., USA).

2.5. Photocatalytic Reaction Setup. The photoreaction system was particularly designed in this experiment and consisted primarily of chamber, lamp, electromagnetic valve, relay, and water bath [22]. Ten open Pyrex vessels of $150 \mathrm{~mL}$ capacity were served as reception receivers in water bath. A $400 \mathrm{~W}$ high-pressure mercury lamp was used as illuminating source for the photocatalytic reaction. The intensity of light irradiation over the surface of the test solution was measured to be $8.42 \mathrm{mWcm}^{-2}(400-1000 \mathrm{~nm})$ and $0.62 \mathrm{mWcm}^{-2}$ (UV $365 \mathrm{~nm}$ ) using FZ-A radiometer and UV-A radiometer (Beijing BNU Light and Electronic Instrumental Co., China), unless otherwise stated.

2.6. Dye Degradation Procedure and Analysis. $0.20 \mathrm{~g}$ of FeAO-n-PAN was immersed into the $50 \mathrm{~mL}$ test solutions containing $0.05 \mathrm{mmol} \mathrm{L}^{-1}$ dye and the appropriate concentration of $\mathrm{H}_{2} \mathrm{O}_{2}$ in the vessel. The temperature in the vessel was kept at $25 \pm 1^{\circ} \mathrm{C}$. The solution in vessel was exposed to the irradiation of lamp in photoreaction system. At the irradiation time intervals, $1-2 \mathrm{~mL}$ of the test solution was taken off from the vessel and rapidly measured at the $\lambda_{\max }$ of the dye used (522 nm for RR 195, $596 \mathrm{~nm}$ for RB 4, and $630 \mathrm{~nm}$ for AB 7) using a UV-2401 Shimadzu spectrophotometer. The decoloration percentage of the dye was expressed as $D \%=$ $\left(1-C / C_{0}\right) \times 100 \%$, where $C_{0}$ is the initial concentration of the dye $\left(\mathrm{mmol} \mathrm{L}^{-1}\right)$ and $C$ is the residual concentration of the dye $\left(\mathrm{mmol} \mathrm{L}^{-1}\right)$. In addition, total organic carbon (TOC) of the test solution was measured by a Phoenix 8000 TOC analyzer (Tekmar-Dohrmann Inc., USA), and TOC removal percentage of the test solution was calculated as follows: TOC removal $\%=\left(1-\mathrm{TOC}_{t} / \mathrm{TOC}_{0}\right) \times 100 \%$, where $\mathrm{TOC}_{0}$ and $\mathrm{TOC}_{t}$ are the TOC values $\left(\mathrm{mgL}^{-1}\right)$ at reaction times 0 and $t$, respectively.

\section{Results and Discussion}

3.1. Morphological Properties and Structure. Figure 2 shows the random orientation and smooth surface of PAN nanofiber, $\mathbf{a}$ and their average diameters are $319.8 \mathrm{~nm}$. Moreover, the surface of PAN nanofibers is rarely affected by the modification and Fe coordination. However, the average diameters of the resulting Fe-AO-n-PAN are $512.8 \mathrm{~nm}$.

Figure 3(a) exhibited the FTIR spectrum of PAN nanofiber. The typical characteristic bands due to the stretching 
<smiles>O=C(O)Oc1ccc(N=Nc2c(S(=O)(=O)O)cc3cc(S(=O)(=O)O)cc(Nc4nc(Cl)nc(Nc5ccc(OC(=O)CCCOS(=O)(=O)O)cc5)n4)c3c2O)cc1</smiles>

Reactive Blue 4<smiles>Nc1c(S(N)(=O)=O)cc(Nc2ccc(Nc3nc(Cl)nc(Cl)n3)c(S(N)(=O)=O)c2)c2c1C(=O)c1ccccc1C2=O</smiles>

Acid Blue 7<smiles>CCN(Cc1ccccc1)c1ccc(C(=C2C=CC(=[N+](CC)Cc3ccccc3)C=C2)c2ccc(S(N)(=O)=O)cc2S(N)(=O)=O)cc1</smiles>

FIGURE 1: Chemical structures of the three dyes.

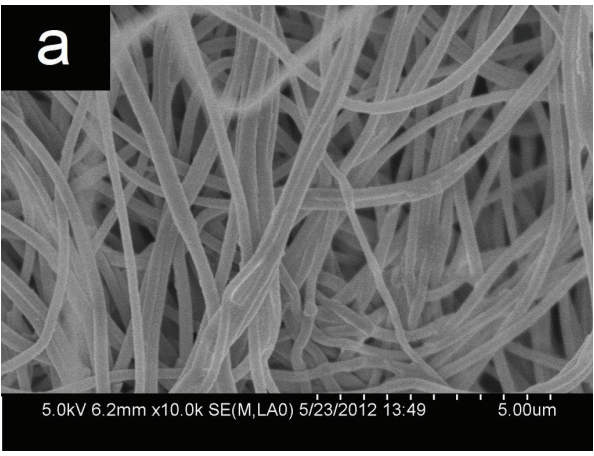

(a)

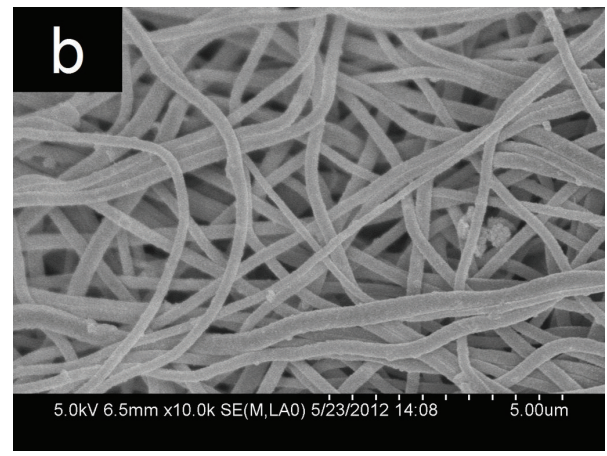

(b)

Figure 2: SEM images of (a) PAN nanofibers and (b) Fe-AO-n-PAN.

vibration of hydroxyl $\left(3540 \mathrm{~cm}^{-1}\right)$, nitrile $\left(2248 \mathrm{~cm}^{-1}\right)$, carbonyl $\left(1738 \mathrm{~cm}^{-1}\right)$, and ether $\left(1250\right.$ and $\left.1150-1040 \mathrm{~cm}^{-1}\right)$ were clearly observed $[6,16]$. The intensity of CN group decreased after modification with hydroxylamine. The characteristic bands of the functional groups of PAN with additional peaks appeared at $1662 \mathrm{~cm}^{-1}$ and $944 \mathrm{~cm}^{-1}$ which is due to the stretching vibration of $\mathrm{N}-\mathrm{O}, \mathrm{N}-\mathrm{H}$ and $\mathrm{C}=\mathrm{N}$ groups in amidoxime, respectively [16]. The intensity of these peaks further decreased and two peaks at 1662 and $944 \mathrm{~cm}^{-1}$ shifted to short position, separately after coordinating with $\mathrm{Fe}^{3+}$ ions in the spectrum of Fe-AO-n-PAN. This demonstrated that the $\mathrm{Fe}^{3+}$ ions were chemically attached to the AO-n-PAN.

3.2. Catalytic Activity of Fe-AO-n-PAN. To study the catalytic property of Fe-AO-n-PAN as a heterogeneous Fenton photocatalyst, the degradation of RR 195 was conducted under the various conditions. For comparison, a control experiment was also performed in the presence of the amidoximated PAN fiber Fe complex (denoted as Fe-AO-PAN) with the PAN yarns using the same method described above, and the results were given in Figure 4.

Figure 4 shows that the $D \%$ value is less than $4.0 \%$ without Fe-AO-n-PAN or Fe-AO-PAN after 90 min of the reaction time under visible irradiation, demonstrating that the decomposition of RR 195 is rather slow in the absence of the catalyst. It is clearly found that when Fe-AO-n-PAN or FeAO-PAN was used, the $D \%$ value increased significantly with the prolongation of the reaction time. These results suggest that Fe-AO-n-PAN or Fe-AO-PAN exhibits strong catalytic activity on the dye degradation. This is because the Fe-AO-nPAN or Fe-AO-PAN can enhance the reduction of the loaded $\mathrm{Fe}^{3+}$ to $\mathrm{Fe}^{2+}$ ions through the Fenton-like process, and the generated $\mathrm{Fe}^{2+}$ ions are then oxidized immediately by $\mathrm{H}_{2} \mathrm{O}_{2}$ to complete the $\mathrm{Fe}^{3+} / \mathrm{Fe}^{2+}$ ions and generate ${ }^{\circ} \mathrm{OH}$ radicals, which is responsible for the dye degradation [23]. Additionally, the photosensitization of the azo dyes can promote a conversion of $\mathrm{Fe}^{3+}$ to $\mathrm{Fe}^{2+}$ ions during photoassisted Fenton reaction $[5,24]$. In this work, it is believed that RR 195 could 


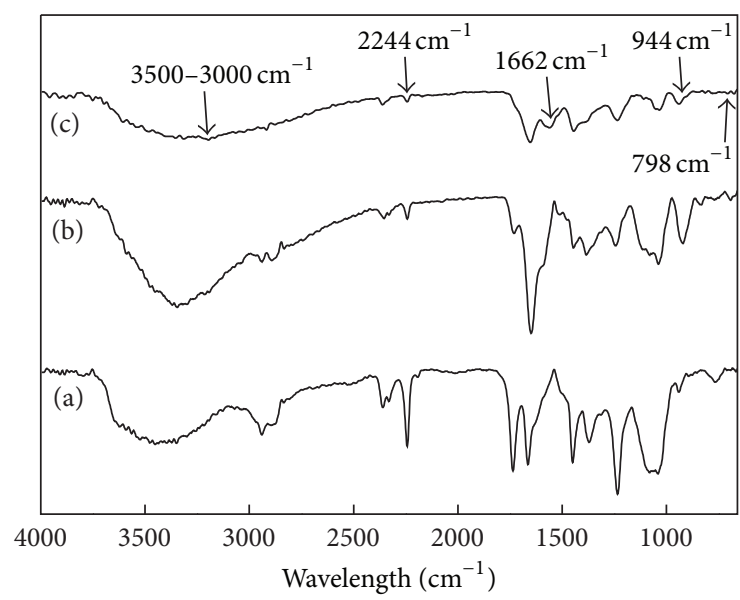

Figure 3: The FTIR spectra of (a) PAN nanofiber, (b) AO-n-PAN, and (c) Fe-AO-n-PAN.

act as the sensitizer of the Fe-AO-n-PAN or Fe-AO-PAN to lead to a charge transfer with the concomitant quenching of the excited dye ${ }^{*}$ and the formation of $\mathrm{dye}^{+}$. These reaction processes are described by

$$
\begin{gathered}
\mathrm{Fe}^{3+} / \mathrm{PAN}+\mathrm{H}_{2} \mathrm{O}_{2} \stackrel{h v / \text { dark }}{\longrightarrow} \mathrm{Fe}^{2+} / \mathrm{PAN}+\mathrm{HO}_{2}{ }^{\bullet}+\mathrm{H}^{\oplus} \\
\mathrm{Fe}^{2+} / \mathrm{PAN}+\mathrm{H}_{2} \mathrm{O}_{2} \longrightarrow \mathrm{Fe}^{3+} / \mathrm{PAN}+\mathrm{OH}^{\ominus}+{ }^{\bullet} \mathrm{OH} \\
\mathrm{Fe}^{3+} / \mathrm{PAN}+\mathrm{HO}_{2} \cdot \longrightarrow \mathrm{Fe}^{2+} / \mathrm{PAN}+\mathrm{O}_{2} \\
\mathrm{Dye}+\mathrm{Fe}^{3+} / \mathrm{PAN} \\
\stackrel{h \nu}{\longrightarrow} \mathrm{Dye}^{*}--\mathrm{Fe}^{3+} / \mathrm{PAN} \\
\longrightarrow \mathrm{Dye}^{+\bullet}+\mathrm{Fe}^{2+} / \text { PAN } \\
\cdot \mathrm{OH}+\mathrm{Dye}^{+\cdot} \text { or Dye } \longrightarrow \text { Products }
\end{gathered}
$$

More importantly, the $\mathrm{D} \%$ values in the case of Fe-AO-nPAN are much higher than those in the case of Fe-AO-PAN, especially in the dark at the same conditions. Furthermore, most of RR 195 molecules were completely decolorized in the presence of Fe-AO-n-PAN within $90 \mathrm{~min}$. These results imply that the Fe-AO-n-PAN exhibits a more remarkable activity for the dye degradation than Fe-AO-PAN. This is mainly attributed to the great specific surface area $\left(3.46 \mathrm{~m}^{2} \mathrm{~g}^{-1}\right)$ of Fe-AO-n-PAN, which is much bigger than that $\left(0.352 \mathrm{~m}^{2} \mathrm{~g}^{-1}\right)$ of Fe-AO-PAN. Besides, the small diameter of the nanofibers could result in a reduced diffusion resistance of the dye and its degradation products due to the short diffusion path [11, 25], thus providing convenient diffusion channels for dye solution and more reaction sites for dye adsorption and degradation.

3.3. Fe Content of Catalyst. The degradation of RR 195 was carried out at $\mathrm{pH} 6$ by the addition of Fe-AO-n-PAN with various $\mathrm{Fe}$ content $\left(Q_{\mathrm{Fe}}\right)$ to the test solutions under light irradiation. The influence of $Q_{\mathrm{Fe}}$ value on the $D \%$ values of RR 195 within 45 min and 90 min was presented in Figure 5.

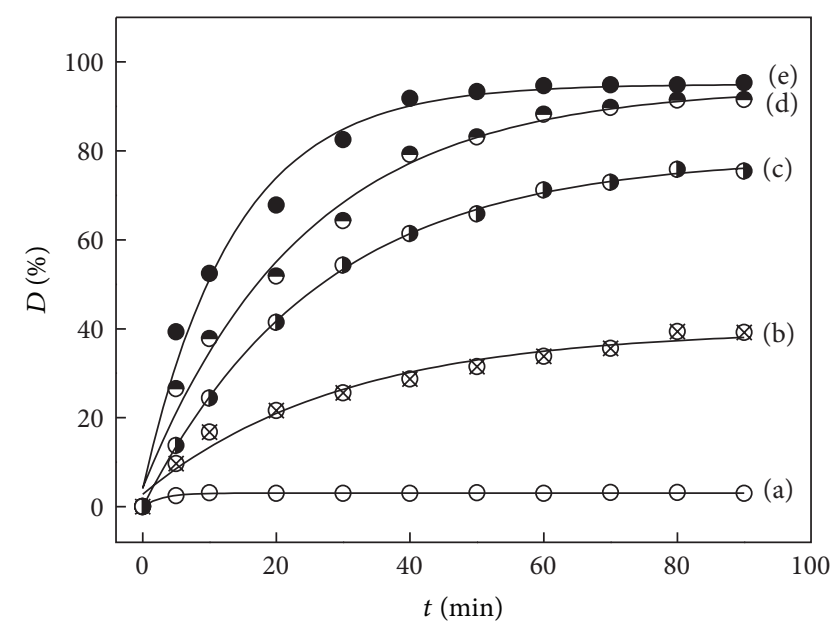

FIgure 4: Variations in D\% values of RR 195 in different systems: (a) RR 195 and $\mathrm{H}_{2} \mathrm{O}_{2}$ under visible irradiation, (b) RR 195, Fe-AOPAN and $\mathrm{H}_{2} \mathrm{O}_{2}$ under dark, (c) RR 195, Fe-AO-PAN, and $\mathrm{H}_{2} \mathrm{O}_{2}$ under visible irradiation, (d) RR 195, Fe-AO-n-PAN, and $\mathrm{H}_{2} \mathrm{O}_{2}$ under dark, and (e) RR 195, Fe-AO-n-PAN, and $\mathrm{H}_{2} \mathrm{O}_{2}$ under visible irradiation. The experiments were carried out under conditions: $\left[\mathrm{H}_{2} \mathrm{O}_{2}\right]=3.0 \mathrm{mmol} \mathrm{L}^{-1}, \mathrm{pH}=6$, Fe-AO-PAN $\left(\mathrm{Q}_{\mathrm{Fe}}=3.42 \mathrm{mmol} \mathrm{g}^{-1}\right)$, or Fe-AO-n-PAN $\left(Q_{\mathrm{Fe}}=3.38 \mathrm{mmol} \mathrm{g}^{-1}\right)=0.20 \mathrm{~g}$

It is seen from Figure 5 that the relatively high $D \%$ values ( $40.2 \%$ for $45 \mathrm{~min}$ and $58.4 \%$ for $90 \mathrm{~min}$ ) were obtained when AO-n-PAN $\left(Q_{\mathrm{Fe}}=0.00 \mathrm{mmolg}^{-1}\right)$ was used as a catalyst. This is because AO-n-PAN has a big specific surface area, leading to a strong adsorption of the dye molecules in solution. Moreover, increasing $Q_{\mathrm{Fe}}$ values of Fe-AO-n-PAN from $0.801 \mathrm{mmol} \mathrm{g}^{-1}$ to $2.25 \mathrm{mmol} \mathrm{g}^{-1}$ is accompanied with a significant enhancement of $D \%$ levels, which are higher than those in the case of AO-n-PAN. This suggests that higher $Q_{\mathrm{Fe}}$ values can significantly accelerate the dye degradation. Similar result was observed for the decomposition of azo dye in the system of Fe-AO-PAN and $\mathrm{H}_{2} \mathrm{O}_{2}$ in our previous work [6]. The possible reason is that increasing $Q_{\mathrm{Fe}}$ values of the catalysts may cause more active sites on their surface, which can improve the $\mathrm{H}_{2} \mathrm{O}_{2}$ decomposition and generate relatively high concentration of ${ }^{\circ} \mathrm{OH}$ radicals in the solution by the heterogeneous photo-Fenton reaction, thus promoting the dye degradation. It is worth noting that little enhancement was observed at $Q_{\mathrm{Fe}}$ being more than $2.25 \mathrm{mmolg}^{-1}$, especially for the $D_{90} \%$ value. This may be owing to the reaction of excess $\mathrm{Fe}^{3+}$ ion with $\mathrm{H}_{2} \mathrm{O}_{2}$ producing less ${ }^{\circ} \mathrm{OH}$ radicals [26]. Therefore, $2.25 \mathrm{mmolg}^{-1}$ of $Q_{\mathrm{Fe}}$ value is believed to be optimum $\mathrm{Fe}$ content of $\mathrm{Fe}-\mathrm{AO}-\mathrm{n}-\mathrm{PAN}$ for the highest catalytic efficiency.

3.4. Initial Concentration of $\mathrm{H}_{2} \mathrm{O}_{2}$. RR 195 was decomposed using Fe-AO-n-PAN $\left(Q_{\mathrm{Fe}}=2.25 \mathrm{mmol} \mathrm{g}^{-1}\right)$ and $\mathrm{H}_{2} \mathrm{O}_{2}$ with the initial concentration $\left(C_{\mathrm{H}_{2} \mathrm{O}_{2}}\right)$ varied from $0 \mathrm{mmol} \mathrm{L}^{-1}$ to $9.00 \mathrm{mmol} \mathrm{L}^{-1}$ at $\mathrm{pH} 6$, and the results were shown in Figure 6.

Figure 6 shows that $D \%$ value increased with the prolongation of reaction time in the absence or presence of 


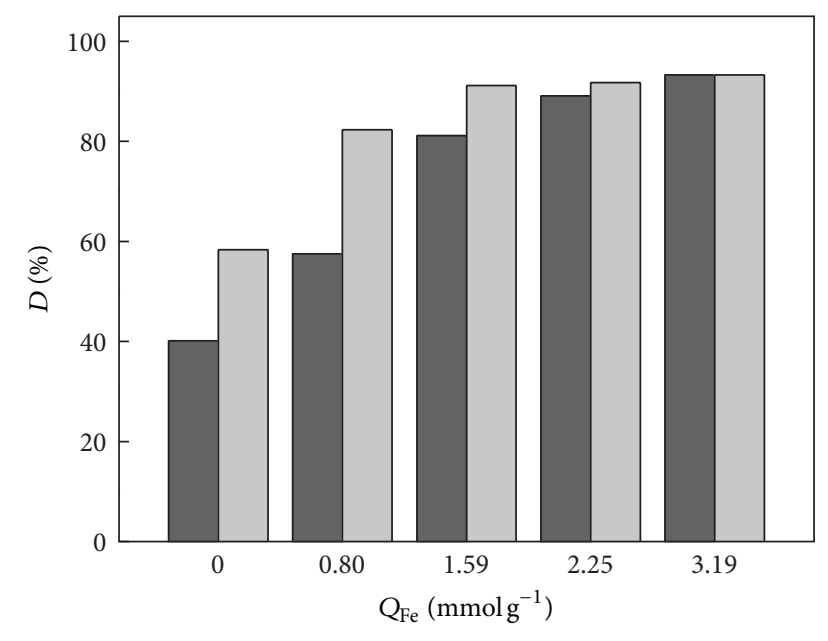

$\square 5 \mathrm{~min}$

FIGURE 5: Degradation of RR 195 by Fe-AO-n-PAN with different $Q_{\mathrm{Fe}}$ values.

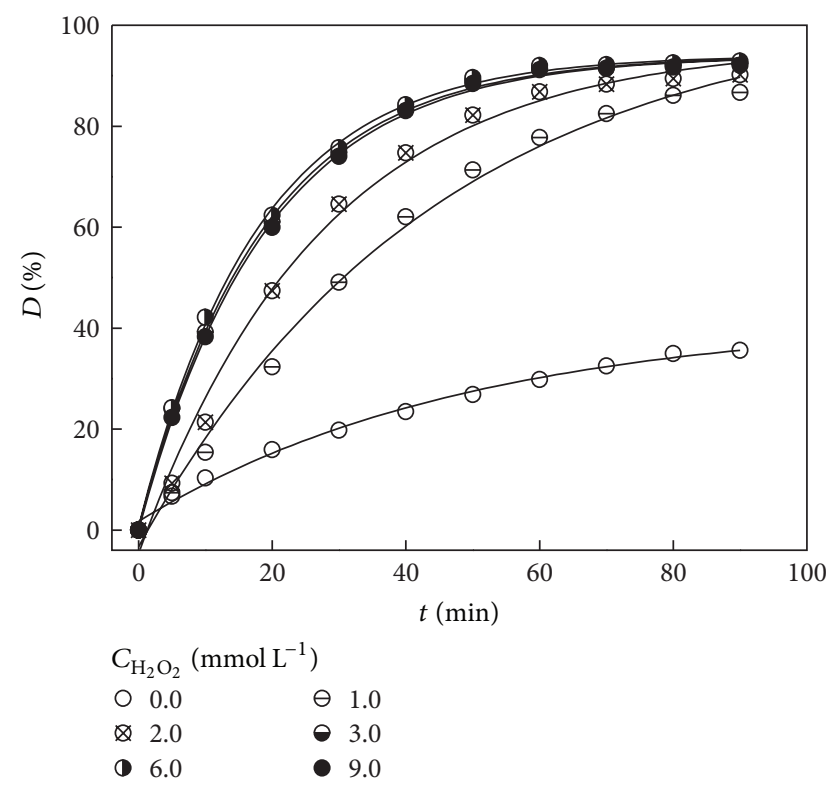

FIGURE 6: Effect of $\mathrm{H}_{2} \mathrm{O}_{2}$ initial concentration on degradation of $\mathrm{RR}$ 195.

$\mathrm{H}_{2} \mathrm{O}_{2}$. And $D \%$ value reached $35.6 \%$ after 90 min without the addition of $\mathrm{H}_{2} \mathrm{O}_{2}$, which is due to the adsorption effect of FeAO-n-PAN with large specific surface area. Moreover, D\% values increased with $C_{\mathrm{H}_{2} \mathrm{O}_{2}}$ increasing from $0 \mathrm{mmol} \mathrm{L}^{-1}$ to $3.00 \mathrm{mmol} \mathrm{L}^{-1}$, indicating that high $\mathrm{C}_{\mathrm{H}_{2} \mathrm{O}_{2}}$ levels led to a gradual increasing $D \%$ values. However, $D \%$ value unremarkably increased when $C_{\mathrm{H}_{2} \mathrm{O}_{2}}$ is above $3.00 \mathrm{mmol} \mathrm{L}^{-1}$. The optimal $C_{\mathrm{H}_{2} \mathrm{O}_{2}}$ level was found to be $3.00 \mathrm{mmol} \mathrm{L}^{-1}$ in this experiment. This is coincident with the results reported in [27]. According to $[28,29]$, the role of $\mathrm{H}_{2} \mathrm{O}_{2}$ in Fenton reaction is different depending on its concentration. At the low $\mathrm{C}_{\mathrm{H}_{2} \mathrm{O}_{2}}$ levels, $\mathrm{H}_{2} \mathrm{O}_{2}$ molecules could not generate enough ${ }^{\circ} \mathrm{OH}$ radicals, resulting in the limited decoloration of RR 195. When $\mathrm{C}_{\mathrm{H}_{2} \mathrm{O}_{2}}$ was over the optimum value, surplus $\mathrm{H}_{2} \mathrm{O}_{2}$ molecules may act as ${ }^{\circ} \mathrm{OH}$ scavenger, thus reducing the ${ }^{\circ} \mathrm{OH}$ concentration in solution $[27,30]$.

3.5. Irradiation Intensity. The degradation of $\mathrm{RR} 195$ was performed at $\mathrm{pH} 6$ with Fe-AO-n-PAN $\left(Q_{\mathrm{Fe}}=2.71 \mathrm{mmol} \mathrm{g}^{-1}\right)$ and $3.0 \mathrm{mmol} \mathrm{L}^{-1} \mathrm{H}_{2} \mathrm{O}_{2}$ under different light irradiations, and $D \%$ values within $45 \mathrm{~min}$ and $90 \mathrm{~min}$ were presented in Table 1 .

It is noticed from Table 1 that RR 195 molecules were partially removed from the test solution in the dark (no light irradiation), which may be attributed to the better adsorption and catalytic capacity of Fe-AO-n-PAN. Moreover, D\% value gradually increased as the irradiation intensity becoming higher. This suggests that stronger light irradiation can significantly enhance catalytic activity of Fe-AO-n-PAN, thus resulting in an obvious improvement in the dye degradation. A main reason is that the amidoximated PAN fiber Fe complex is activated throughout the UV and visible wavelengths where light absorption occurs [6]. Consequently, Fe$\mathrm{AO}-\mathrm{n}-\mathrm{PAN}$ is regarded as an efficient Fenton photocatalyst for dyeing wastewater. Another explanation is that higher irradiation may increase the photosensitization of the dye molecules on the surface of catalyst, which promotes a conversion of $\mathrm{Fe}^{3+}$ to $\mathrm{Fe}^{2+}$ ions during the degradation. Besides, higher irradiation may be beneficial for photolysis of $\mathrm{H}_{2} \mathrm{O}_{2}$ and photoreduction of $\mathrm{Fe}^{3+}$ to $\mathrm{Fe}^{2+}$ ions in the solution since both processes are strongly dependent on wavelength and intensity of light irradiation [31]. Finally, it is possible that powerful light irradiation may change the aggregation equilibrium of dye molecules in solution, and reduce the formation of dye aggregation units due to their weak stability in aqueous solution [32].

3.6. Dye Structure Characteristics and Initial Concentration. The comparative study was carried out for the degradation of three kinds of textile dyes: azo dye, RR 195; anthraquinone dye, $\mathrm{RB} 4$, and triphenylmethane dye, $\mathrm{AB} 7$ from aqueous solution by Fe-AO-n-PAN $\left(Q_{\mathrm{Fe}}=2.71 \mathrm{mmol} \mathrm{g}^{-1}\right)$ and $3.0 \mathrm{mmol} \mathrm{L}^{-1} \mathrm{H}_{2} \mathrm{O}_{2}$ at $\mathrm{pH} 6$ under light irradiation. The $\mathrm{UV}$-Vis spectrum analysis was adopted to investigate their degradation and intermediate transformation during treatments. The comparisons of UV-Vis spectra of dye degradation processes are given in Figure 7. Moreover, D\% values of three dyes were also calculated and shown in Figure 7.

Figures 7(a)-7(c) show that three characteristic peaks at $522 \mathrm{~nm}$ for RR 195, $596 \mathrm{~nm}$ for RB 4, and $630 \mathrm{~nm}$ for AB 7 decreased gradually with prolonging irradiation time. As shown in Figure $7(\mathrm{~d})$, their D\% values were above $90 \%$ within $45 \mathrm{~min}$. These results suggest that chromophores of three dyes have been almost completely destructed after the degradation. Not only characteristic peaks of three dyes, but also some peaks (296 nm for RR 195, $256 \mathrm{~nm}$ and $296 \mathrm{~nm}$ for $\mathrm{RB} 4$, and $307 \mathrm{~nm}$ for AB 7) in 200-400 $\mathrm{nm}$ also significantly decreased during the degradation processes, which indicated that the aromatic rings of three dye molecules studied 


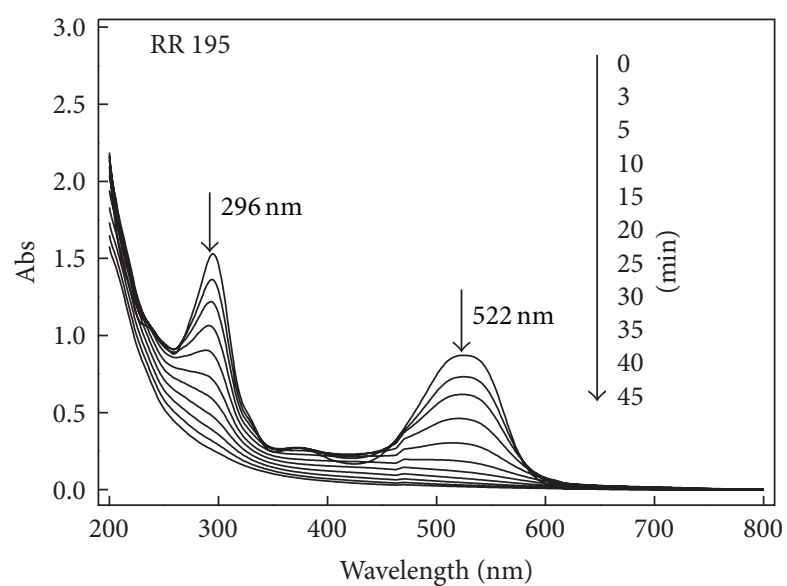

(a)

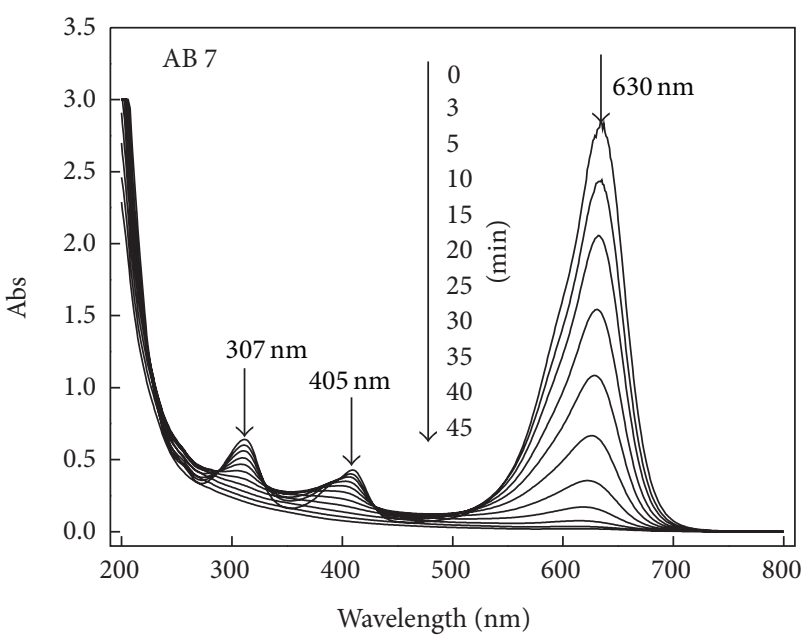

(c)

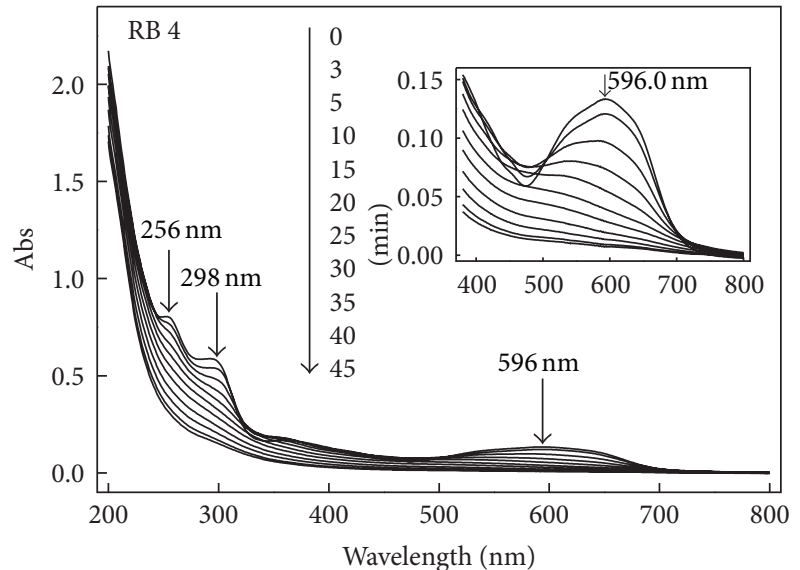

(b)

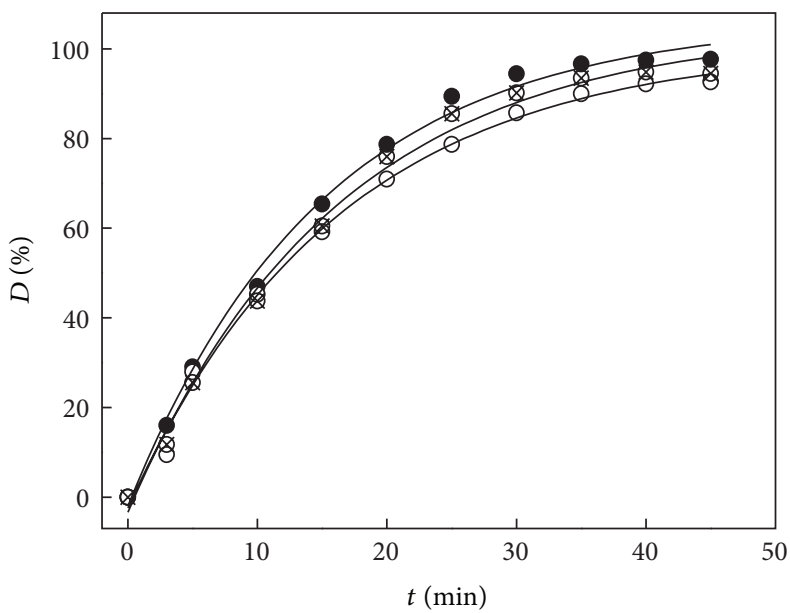

- RR 195

$\otimes \mathrm{AB} 7$

O RB 4

FIGURE 7: Degradation of three dyes with different molecular structures.

TABLE 1: Degradation of RR 195 under increasing light irradiations.

\begin{tabular}{lccccc}
\hline \multirow{2}{*}{ Irradiation intensity } & Visible $_{(400-1000 \mathrm{~nm})}\left(\mathrm{m} \mathrm{W} \mathrm{cm}^{-2}\right)$ & 0 & 8.42 & 11.3 & 15.4 \\
& $\mathrm{UV}_{(365 \mathrm{~nm})}\left(\mathrm{m} \mathrm{W} \mathrm{cm}^{-2}\right)$ & 0 & 0.62 & 0.72 & 1.04 \\
\hline \multirow{2}{*}{$D \%$} & $45 \mathrm{~min}$ & 61.04 & 79.47 & 88.82 & 98.40 \\
& $90 \mathrm{~min}$ & 82.35 & 91.25 & 97.02 & 99.89 \\
\hline
\end{tabular}

were destroyed by the photocatalysis of Fe-AO-n-PAN/ $\mathrm{H}_{2} \mathrm{O}_{2}$. Consequently, Fe-AO-n-PAN was proved to be a universal and efficient catalyst for degradation of the three dyes with different molecular structures.

In order to investigate the effect of dye initial concentration on its degradation, we performed the experiments with four initial concentrations of RR 195 under light irradiation while the other variables were kept constant. It is apparent from Figure 8 that higher initial concentrations can cause a dramatic reduction in $D \%$ values, proposing that the lower the RR 195 initial concentration, the shorter the reaction period needed to degrade RR 195 completely. D\% values, especially for low RR 195 initial concentration, increased quickly in the first $20 \mathrm{~min}$ and then obviously slowed down as time goes on. This is because when the $\mathrm{H}_{2} \mathrm{O}_{2}$ concentration was kept constant for the solutions with different RR 195 initial concentrations, more $\mathrm{H}_{2} \mathrm{O}_{2}$ molecules were consumed in the beginning stage [33]. On the other hand, it is well known that the aggregation equilibrium of dye molecules in water is affected particularly by dye concentration 


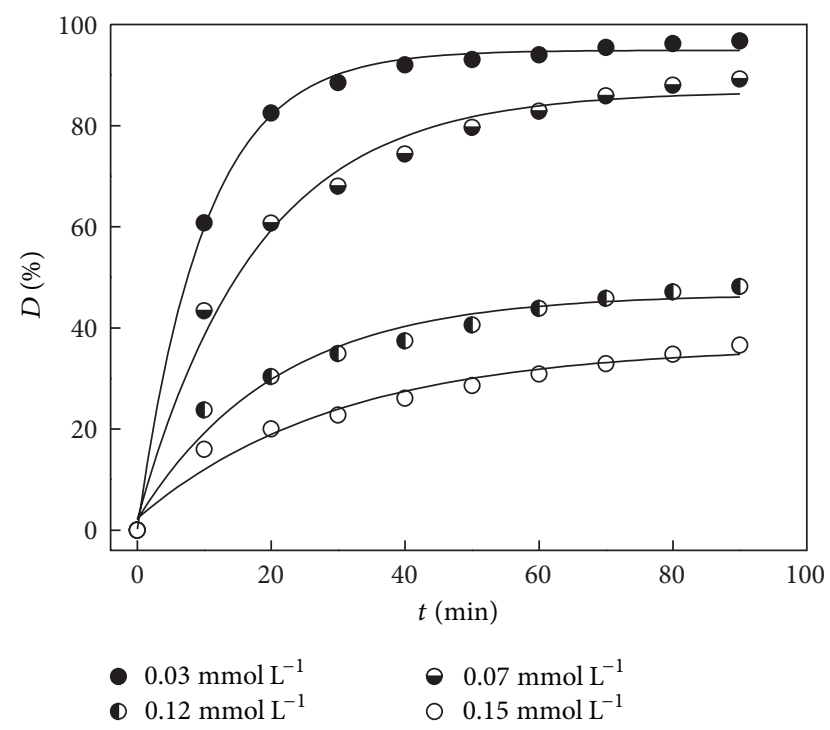

Figure 8: The degradation of RR 195 with different initial concentrations, experimental conditions: $0.20 \mathrm{~g}$ Fe-AO-n-PAN $\left(Q_{\mathrm{Fe}}=\right.$ $2.15 \mathrm{mmolg}^{-1}$ ), $\mathrm{H}_{2} \mathrm{O}_{2}: 3.0 \mathrm{mmol} \mathrm{L}^{-1}$, and $\mathrm{pH}=6$.

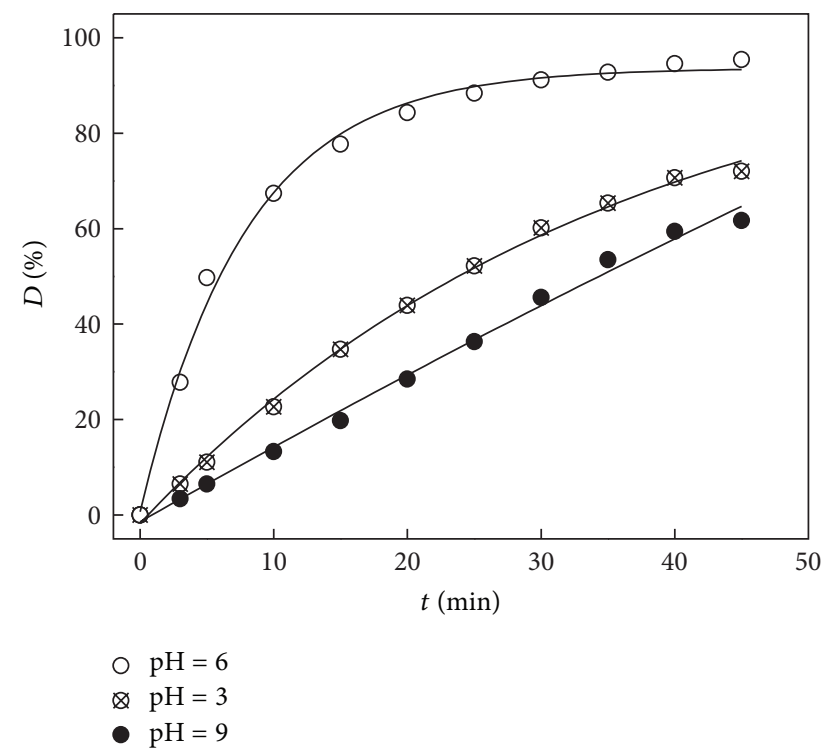

FIgURE 9: Degradation of RR 195 with Fe-AO-n-PAN in different $\mathrm{pH}$ levels.

$[34,35]$. Higher dye concentration can generally enhance the formation of dye aggregation units, which limits the dye adsorption and degradation.

3.7. The Solution $p H$. The degradation of $\mathrm{RR} 195$ with $3.0 \mathrm{mmol} \mathrm{L}^{-1} \mathrm{H}_{2} \mathrm{O}_{2}$ catalyzed by Fe-AO-n-PAN $\left(Q_{\mathrm{Fe}}=\right.$ $\left.3.71 \mathrm{mmol} \mathrm{g}^{-1}\right)$ at different solution $\mathrm{pH}$ was investigated under light irradiation in order to ensure the stability of FeAO-n-PAN as a photocatalyst over a wide $\mathrm{pH}$ range, and the experimental result was presented in Figure 9.

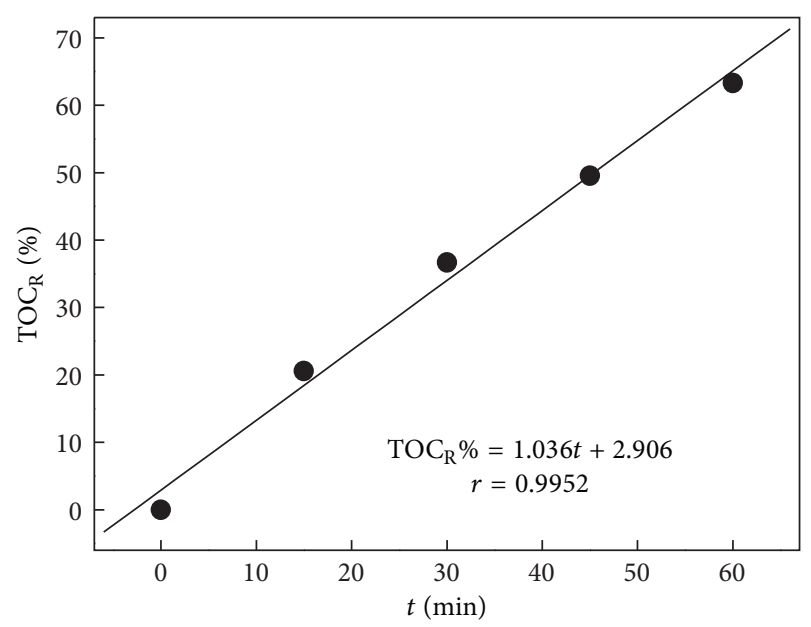

FIgURE 10: TOC $_{\mathrm{R}} \%$ values of RR 195 solution as a function of the reaction time.

It was clearly observed from Figure 9 that $D \%$ values as a function of the reaction time when initial solution $\mathrm{pH}$ is varied. The dye degradation occurred over a wide range of $\mathrm{pH}$ values from 3 to 9 . $D \%$ value reached the maximum value of $95.42 \%$ at $\mathrm{pH} 6$ within $45 \mathrm{~min}$. $\mathrm{D} \%$ value at $\mathrm{pH}$ 3 was higher than that at $\mathrm{pH} 9$ at the same reaction time. These results demonstrated that Fe-AO-n-PAN exhibited a higher catalytic activity at acidic medium than at alkaline medium, and its highest catalytic efficiency could be obtained at $\mathrm{pH}$ 6. This optimum solution $\mathrm{pH}$ is higher than $\mathrm{pH}$ level (about 3.0) at which homogeneous photoassisted Fenton reaction was performed most easily [36]. On the other hand, the change in the $\mathrm{pH}$ of the reaction system during the degradation of RR 195 was obviously found. For instance, the final $\mathrm{pH}$ value after $45 \mathrm{~min}$ of reaction was about 2.6 for an initial $\mathrm{pH}$ of 6 . This may be owing to the acidity of the intermediates produced during the degradation [33]. Some similar phenomena were observed by Feng et al. [33] and Dhananjeyan et al. [37].

3.8. Mineralization. Mineralization of the dye molecules in solution should be examined since the degradation intermediates may be longer-lived and even more toxic than the parent dyes to aquatic animals and human beings. In this work, mineralization of RR 195 was performed in the presence of $3.0 \mathrm{mmol} \mathrm{L}^{-1} \mathrm{H}_{2} \mathrm{O}_{2}$ and Fe-AO-n-PAN $\left(Q_{\mathrm{Fe}}=\right.$ $2.71 \mathrm{mmol} \mathrm{g}^{-1}$ ) at $\mathrm{pH} 6$ under light irradiation, and the result is given in Figure 10.

Figure 10 shows that $\mathrm{TOC}_{R} \%$ value increases proportionally as the reaction time goes on. A linear equation between $\mathrm{TOC}_{\mathrm{R}} \%$ value and reaction time $(t)$ also is also provided. Moreover, TOC $_{R} \%$ value reaches $63.28 \%$ within 60 min under light irradiation. These results illustrates that RR 195 molecules can be destructed and then converted into $\mathrm{H}_{2} \mathrm{O}, \mathrm{CO}_{2}$, and inorganic salts. This is in good agreement with the decoloration and degradation of the RR 195 mentioned above. 


\section{Conclusions}

The modified PAN nanofiber Fe complex was prepared through the amidoximation and consequent Fe coordination of PAN nanofiber obtained using electrospinning technique. This complex not only significantly catalyzed the oxidative degradation of the textile dye in water as a novel heterogeneous Fenton photocatalyst, but also showed a better catalytic performance than the Fe complex prepared with conventional PAN yarns in the dark or under light irradiation. It was found that $\mathrm{Fe}$ content of the complex, $\mathrm{H}_{2} \mathrm{O}_{2}$ initial concentration, irradiation intensity, and the solution $\mathrm{pH}$ were the main factors that have strong impacts on the heterogeneous Fenton degradation of the textile dye. Increasing Fe content of the complex or irradiation intensity would accelerate the dye degradation. The optimal $\mathrm{H}_{2} \mathrm{O}_{2}$ molar concentration is $3.0 \mathrm{mmol} \mathrm{L}^{-1}$ in order to obtain the best decoloration efficiency. Although this complex has a relatively better catalytic activity over a wide $\mathrm{pH}$ range, the optimal $\mathrm{pH}$ of the reaction solution is 6 for the fastest degradation of the dye. Moreover, it was proved that the modified PAN nanofiber Fe complex was a universal and efficient catalyst for degradation of the three classes of textile dyes including azo dye, anthraquinone dye, and triphenylmethane dye. Besides, UV-Vis spectrum analysis and TOC measurement indicated that the chromophore and aromatic rings of the dye molecules were decomposed and then converted into $\mathrm{H}_{2} \mathrm{O}$, $\mathrm{CO}_{2}$, and inorganic salts in the presence of the modified PAN nanofiber Fe complex and $\mathrm{H}_{2} \mathrm{O}_{2}$ under light irradiation.

\section{Acknowledgments}

The authors thank the Tianjin Municipal Science and Technology Committee for the Research Programs of Application Foundation and Advanced Technology (11JCZDJ24600, 11ZCKFGX03200). This research was also supported in part by the grants from the Natural Science Foundation of China (20773093, 51102178).

\section{References}

[1] B. Lodha and S. Chaudhari, "Optimization of Fenton-biological treatment scheme for the treatment of aqueous dye solutions," Journal of Hazardous Materials, vol. 148, no. 1-2, pp. 459-466, 2007.

[2] E. Abadulla, T. Tzanov, S. Costa, K.-H. Robra, A. CavacoPaulo, and G. M. Gubitz, "Decolorization and detoxification of textile dyes with a laccase from Trametes hirsuta," Applied and Environmental Microbiology, vol. 66, no. 8, pp. 3357-3362, 2000.

[3] A. Mittal, V. Gajbe, and J. Mittal, "Removal and recovery of hazardous triphenylmethane dye, Methyl Violet through adsorption over granulated waste materials," Journal of Hazardous Materials, vol. 150, no. 2, pp. 364-375, 2008.

[4] W. J. Epolito, Y. H. Lee, L. A. Bottomley, and S. G. Pavlostathis, "Characterization of the textile anthraquinone dye Reactive Blue 4," Dyes and Pigments, vol. 67, no. 1, pp. 35-46, 2005.

[5] Z. Ding, Y. Dong, and B. Li, "Preparation of a modified PTFE fibrous photo-Fenton catalyst and its optimization towards the degradation of organic dye," International Journal of Photoenergy, vol. 2012, Article ID 121239, 8 pages, 2012.
[6] Y. Dong, Z. Han, C. Liu, and F. Du, "Preparation and photocatalytic performance of Fe (III)-amidoximated PAN fiber complex for oxidative degradation of azo dye under visible light irradiation," Science of the Total Environment, vol. 408, no. 10, pp. 2245-2253, 2010.

[7] L. Wan, Z. Xu, and H. Jiang, "Fibrous membranes electrospinning from acrylonitrue-based polymers: specific absorption behaviors and states of water," Macromolecular Bioscience, vol. 6, no. 5, pp. 364-372, 2006.

[8] H. Zhang, H. Nie, D. Yu et al., "Surface modification of electrospun polyacrylonitrile nanofiber towards developing an affinity membrane for bromelain adsorption," Desalination, vol. 256, no. 1-3, pp. 141-147, 2010.

[9] K. Yoon, B. S. Hsiao, and B. Chu, "High flux nanofiltration membranes based on interfacially polymerized polyamide barrier layer on polyacrylonitrile nanofibrous scaffolds," Journal of Membrane Science, vol. 326, no. 2, pp. 484-492, 2009.

[10] A. Sato, R. Wang, H. Ma, B. S. Hsiao, and B. Chu, "Novel nanofibrous scaffolds for water filtration with bacteria and virus removal capability," Journal of Electron Microscopy, vol. 60, no. 3, pp. 201-209, 2011.

[11] Q. Feng, Q. Wang, B. Tang et al., "Immobilization of catalases on amidoxime polyacrylonitrile nanofibrous membranes," Polymer International, vol. 62, no. 2, pp. 251-256, 2013.

[12] S. Li, J. Chen, and W. Wu, "Electrospun polyacrylonitrile nanofibrous membranes for lipase immobilization," Journal of Molecular Catalysis B, vol. 47, no. 3-4, pp. 117-124, 2007.

[13] S. Li and W. Wu, "Lipase-immobilized electrospun PAN nanofibrous membranes for soybean oil hydrolysis," Biochemical Engineering Journal, vol. 45, no. 1, pp. 48-53, 2009.

[14] N. Zhou, T. Yang, C. Jiang, M. Du, and K. Jiao, "Highly sensitive electrochemical impedance spectroscopic detection of DNA hybridization based on Aunano-CNT/PANnano films," Talanta, vol. 77, no. 3, pp. 1021-1026, 2009.

[15] P. Kampalanonwat and P. Supaphol, "Preparation and adsorption behavior of aminated electrospun polyacrylonitrile nanofiber mats for heavy metal ion removal," ACS Applied Materials and Interfaces, vol. 2, no. 12, pp. 3619-3627, 2010.

[16] K. Saeed, S. Park, and T. Oh, "Preparation of hydrazinemodified polyacrylonitrile nanofibers for the extraction of metal ions from aqueous media," Journal of Applied Polymer Science, vol. 121, no. 2, pp. 869-873, 2011.

[17] Q. Feng, X. Wang, A. Wei et al., "Surface modified ployacrylonitrile nanofibers and application for metal ions chelation," Fibers and Polymers, vol. 12, no. 8, pp. 1025-1029, 2011.

[18] S. Li, X. Yue, Y. Jing, S. Bai, and Z. Dai, "Fabrication of zonal thiol-functionalized silica nanofibers for removal of heavy metal ions from wastewater," Colloids and Surfaces A, vol. 380, no. 1-3, pp. 229-233, 2011.

[19] K. Saeed, S. Haider, T. Oh, and S. Park, "Preparation of amidoxime-modified polyacrylonitrile (PAN-oxime) nanofibers and their applications to metal ions adsorption," Journal of Membrane Science, vol. 322, no. 2, pp. 400-405, 2008.

[20] Z. Han, Y. Dong, and S. Dong, "Comparative study on the mechanical and thermal properties of two different modified PAN fibers and their Fe complexes," Materials and Design, vol. 31, no. 6, pp. 2784-2789, 2010.

[21] Y. Kim, C. H. Ahn, M. B. Lee, and M. Choi, "Characteristics of electrospun $\mathrm{PVDF} / \mathrm{SiO}_{2}$ composite nanofiber membranes as polymer electrolyte," Materials Chemistry and Physics, vol. 127, no. 1-2, pp. 137-142, 2011. 
[22] Y. Dong, W. Dong, Y. Cao, Z. Han, and Z. Ding, "Preparation and catalytic activity of $\mathrm{Fe}$ alginate gel beads for oxidative degradation of azo dyes under visible light irradiation," Catalysis Today, vol. 175, no. 1, pp. 346-355, 2011.

[23] Y. Han, Y. Dong, Z. Ding, and C. Liu, "Influence of polypropylene fibers on preparation and performance of Fe-modified PAN/PP blended yarns and their knitted fabrics," Textile Research Journal, vol. 83, no. 3, pp. 219-228, 2013.

[24] J. F. Wei, Z. P. Wang, J. Zhang, Y. Y. Wu, Z. P. Zhang, and C. H. Xiong, "The preparation and the application of grafted polytetrafluoroethylene fiber as a cation exchanger for adsorption of heavy metals," Reactive and Functional Polymers, vol. 65, no. 1-2, pp. 127-134, 2005.

[25] S. Sakai, K. Antoku, T. Yamaguchi, and K. Kawakami, "Development of electrospun poly(vinyl alcohol) fibers immobilizing lipase highly activated by alkyl-silicate for flow-through reactors," Journal of Membrane Science, vol. 325, no. 1, pp. 454-459, 2008.

[26] I. Muthuvel and M. Swaminathan, "Photoassisted Fenton mineralisation of Acid Violet 7 by heterogeneous $\mathrm{Fe}(\mathrm{III})-\mathrm{Al} 2 \mathrm{O} 3$ catalyst," Catalysis Communications, vol. 8, no. 7, pp. 981-986, 2007.

[27] Y. Dong, L. He, and M. Yang, "Solar degradation of two azo dyes by photocatalysis using $\mathrm{Fe}(\mathrm{III})$-oxalate complexes $/ \mathrm{H}_{2} \mathrm{O}_{2}$ under different weather conditions," Dyes and Pigments, vol. 77, no. 2, pp. 343-350, 2008.

[28] S. Kaur and V. Singh, " $\mathrm{TiO}_{2}$ mediated photocatalytic degradation studies of Reactive Red 198 by UV irradiation," Journal of Hazardous Materials, vol. 141, no. 1, pp. 230-236, 2007.

[29] C. M. So, M. Y. Cheng, J. C. Yu, and P. K. Wong, "Degradation of azo dye Procion Red MX-5B by photocatalytic oxidation," Chemosphere, vol. 46, no. 6, pp. 905-912, 2002.

[30] M. Muruganandham and M. Swaminathan, "Photochemical oxidation of reactive azo dye with $\mathrm{UV}-\mathrm{H}_{2} \mathrm{O}_{2}$ process," Dyes and Pigments, vol. 62, no. 3, pp. 269-275, 2004.

[31] B. Muthukumari, K. Selvam, I. Muthuvel, and M. Swaminathan, "Photoassisted hetero-Fenton mineralisation of azo dyes by $\mathrm{Fe}(\mathrm{II})-\mathrm{Al} 2 \mathrm{O} 3$ catalyst," Chemical Engineering Journal, vol. 153, no. 1-3, pp. 9-15, 2009.

[32] Y. Dong, W. Dong, C. Liu, Y. Chen, and J. Hua, "Photocatalytic decoloration of water-soluble azo dyes by reduction based on bisulfite-mediated borohydride," Catalysis Today, vol. 126, no. 3-4, pp. 456-462, 2007.

[33] J. Feng, X. Hu, P. L. Yue, H. Y. Zhu, and G. Q. Lu, “Degradation of azo-dye orange II by a photoassisted Fenton reaction using a novel composite of iron oxide and silicate nanoparticles as a catalyst," Industrial and Engineering Chemistry Research, vol. 42, no. 10, pp. 2058-2066, 2003.

[34] W. S. Perkins, Textile Coloration and Finishing, China Textile Press, Beijing, China, 2004.

[35] M. M. El-Fass, N. A. Badawy, A. A. El-Bayaa, and N. S. Moursy, "The influence of simple electrolyte on the behavior of some acid dyes in aqueous media," Bulletin of the Korean Chemical Society, vol. 16, no. 5, pp. 458-461, 1995.

[36] M. Hartmann, S. Kullmann, and H. Keller, "Wastewater treatment with heterogeneous Fenton-type catalysts based on porous materials," Journal of Materials Chemistry, vol. 20, no. 41, pp. 9002-9017, 2010.

[37] M. R. Dhananjeyan, J. Kiwi, P. Albers, and O. Enea, "Photoassisted immobilized Fenton degradation up to $\mathrm{pH} 8$ of azo dye Orange II mediated by $\mathrm{Fe}^{+} /$Nafion/glass fibers," Helvetica Chimica Acta, vol. 84, no. 11, pp. 3433-3445, 2001. 

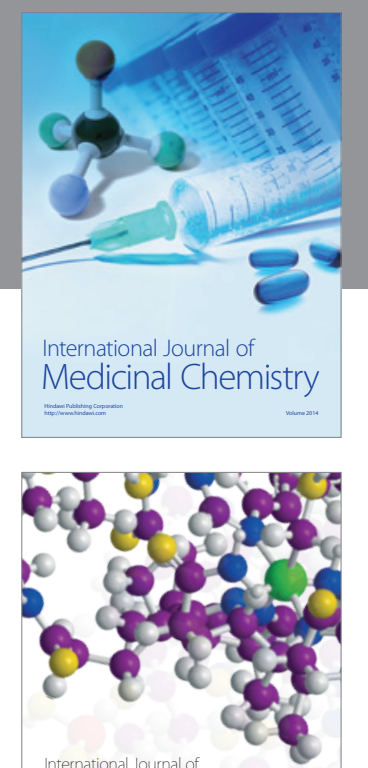

\section{Carbohydrate} Chemistry

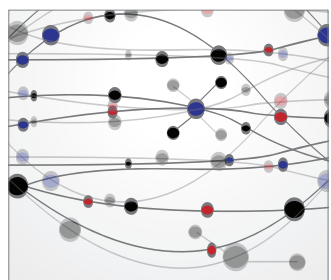

The Scientific World Journal
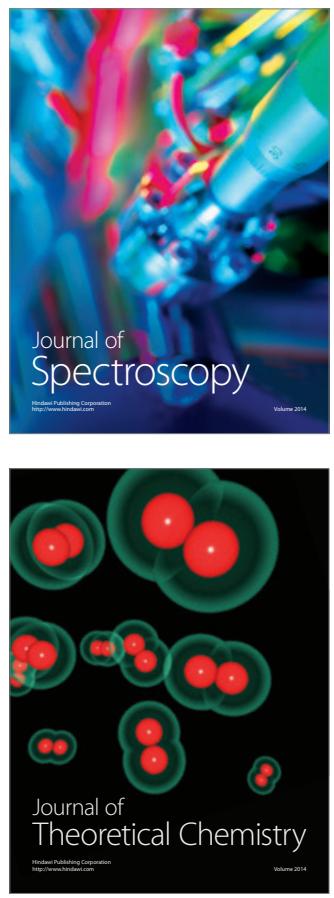
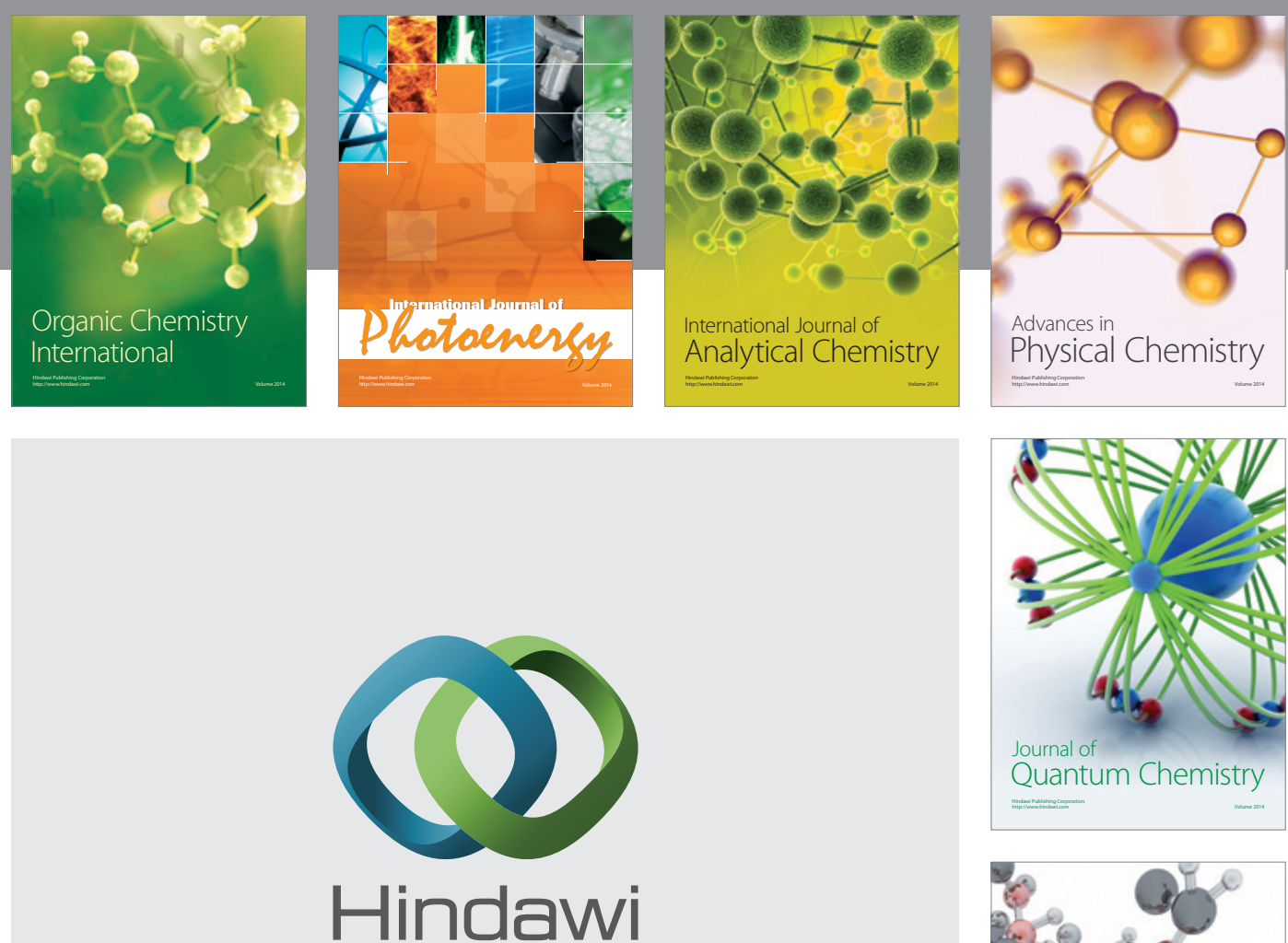

Submit your manuscripts at

http://www.hindawi.com

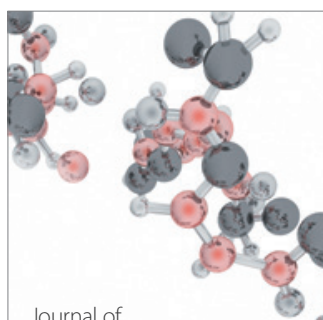

Analytical Methods

in Chemistry

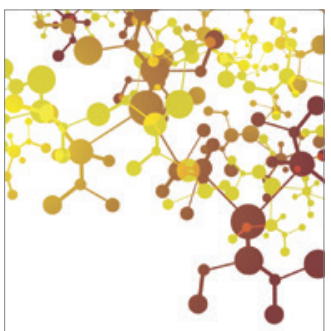

Journal of

Applied Chemistry

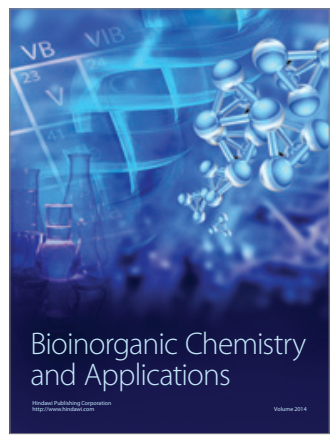

Inorganic Chemistry
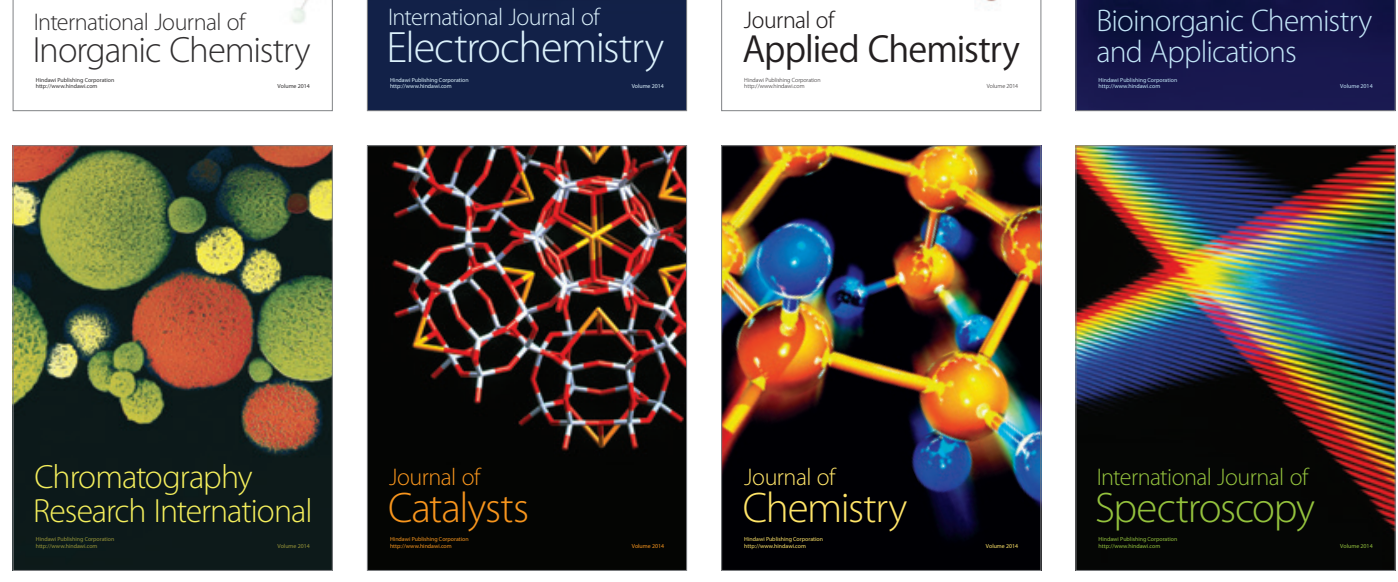